UNCERTAINTY AND THE THEORY OF

\title{
MARK-UP PRICING
}

\author{
Robert W. Fraser \\ Department of Economics \\ University of Western Australia \\ Discussion Paper 84.04 \\ March 1984
}

ISSN 0811-6067

ISBN $086422608 \mathrm{x}$ 


\section{ABSTRACT}

This paper examines the role of demand uncertainty in influencing a firm's mark-up pricing decision. With no uncertainty the marginalist approach represents this mark-up as inversely and solely determined by the elasticity of demand. Here it is shown that the introduction of uncertainty does not alter this simple dependency for a risk neutral firm. For a risk averse firm, however, the mark-up is shown to depend on a range of factors, including the level of fixed and variable costs and the level of expected demand. It is argued that such variability of margin is more in keeping with observed behaviour. 
INTRODUCTION

In his recent discussion of the prospects of the Economics of Uncertainty, John Hey (1982) concludes that "the Economics of Uncertainty must abandon its pre-occupation with optimal rules of behaviour, and concentrate instead on reasonable rules of thumb". In the context of the theory of the firm, one such rule of thumb which has been of interest to economists since the work of $\mathrm{Hall}$ and Hitch (1939) is that of average cost pricing. In this situation a firm, when faced with the problem of deciding which price to charge for its products, sets this price equal to some percentage "mark-up" on "average costs". While the constitution of "average costs" has been of some interest to economists, by far the most considered issue has been the determinants of the size of the "mark-up".

The post-Keynesian approach, as represented by Harcourt and Kenyon (1976), is to argue that the mark-up is set at such a level as is expected to provide adequate funds to finance the firm's investment programme: "Thus actual prices do not reflect current demand conditions; rather they reflect the funds requirements for the planned investment expenditure the firm considers necessary if it is to adjust its capacity sufficiently to meet expected future demand". ${ }^{2}$ This neglect of demand influences seems, however, to be too extreme. As Hay and Morris (1979) conclude after a survey of relevant econometric evidence "demand elements as well as cost elements are important in price setting". 3

Furthermore, this evidence can be used to criticise the marginalist approach to the determination of the mark-up. In this approach the margin is selected so as to maximise profits, yielding a value which

1. Hey (1982), p.139.

2. Kenyon (1978), p.40.

3. Hay and Morris (1979), p.135. 
is inversely, and solely, related to the product's elasticity of demand. Consequently, the only consideration of demand factors is through this elasticity. This means that shifts in demand which leave elasticity unchanged will not result in the firm adjusting its "optimal" profit margin. This independence of the size of margin from the level of demand is, therefore, also in conflict with available evidence.

In general then, it would seem that these theories of mark-up determination are too simplistic to account for the behaviour of firms. This conclusion implies, however, not that the fault lies in the rule itself but rather in each theory's overly-simplified structuring of the firm's problem. In other words, although there is much evidence to support the prevalence of mark-up pricing among firms, this evidence does not support the notion that the mark-up is determined in a simple fashion. Consistent with this line of thought is the view of Hay and Morris (1979) that: "Clearly average cost pricing with adjustable margins can be seen as a reaction to complexity and uncertainty about demand conditions". 4 This suggests that a better understanding of the determinants of the mark-up may be achieved by a more explicit recognition of the role of uncertainty in the firm's economic environment. The intention of this paper is to develop a theory of mark-up pricing which makes explicit the role of demand uncertainty in determining the size of the mark-up. While retaining the marginalist approach, specifically by assuming that the firm is an expected utility maximiser, it can be shown that the size of the firm's mark-up is dependent on many factors other than the elasticity of demand, thereby developing more precisely the concept of "adjustable margins".

The plan of the paper is as follows: Section I introduces the basic model of the firm's choice of mark-up in the face of demand

4. Hay and Morris (1979), p.123. 
uncertainty. It is shown that although the marginalist approach to the mark-up decision is unaltered by the introduction of demand uncertainty if the firm is risk neutral, a risk averse firm's mark-up will depend on the presence or not of uncertainty. Section II considers some comparative static results of the basic model and shows that the optimal mark-up depends on such things as the level of expected demand, the level of demand uncertainty and the level of fixed and variable costs. These results contrast strongly with the determination of the mark-up in the certainty theory. Section III concludes the paper.

\section{SECTION I THE MODEL}

This section considers the marginalist approach to a firm's choice of profit margin. It is assumed that the mark-up is set as a percentage of the firm's average variable cost, which itself is assumed to be constant over the relevant range of output: ${ }^{5}$

$$
\mathrm{P}=(1+\lambda) \mathrm{c}
$$

$$
\text { where: } \begin{aligned}
\mathrm{p} & =\text { price } \\
\lambda & =\text { mark-up } \\
\mathrm{c} & =\text { average variable cost (= marginal cost) }
\end{aligned}
$$

The firm's demand curve is assumed to be downward sloping with a constant elasticity:

$$
x=p^{-\varepsilon}
$$

where $\quad \mathbf{x}=$ demand (and output)

$\varepsilon=$ elasticity of demand

The firm's profit ( $\pi$ ) is thus given by:

5. Hay and Morris (1979) cite evidence to support both of these assumptions. 


$$
\begin{aligned}
\pi & =p \cdot x-c \cdot x-B \\
& =\lambda c \cdot([1+\lambda] c)^{-E}-B
\end{aligned}
$$

where: $\quad B=$ fixed cost

Differentiating (3) with respect to $\lambda$ and setting equal to zero gives:

$$
\frac{\partial \pi}{\partial \lambda}=c \cdot([1+\lambda] c)^{-\varepsilon}-\varepsilon \lambda c^{2}([1+\lambda] c)^{-\varepsilon}-1=0
$$

which can be simplified to give:

$$
c^{2} \cdot([1+\lambda] c)^{-\varepsilon-1}(1+\lambda-\varepsilon \lambda)=0
$$

The firm's optimal mark-up is thus given by:

$$
\lambda=\frac{1}{E-1}
$$

Equation (4) is the standard result of the literature: the firm's mark-up depends inversely and solely on the elasticity of demand for its product. Note also that (4) implies $\varepsilon>1$.

To introduce uncertainty about demand into the firm's problem, let the actual level of demand depend on both the set price and a random shift term $(\mu):^{6}$

$$
x=p^{-\varepsilon}+\mu
$$

where: $E(\mu)=0$

$$
\overline{\mathrm{x}}=\text { expected demand }=\mathrm{p}^{-\varepsilon}
$$

In the case represented by (5), the firm must choose its price before the actual level of demand associated with that price is realised. It

6. Attempts to analyse the behaviour of a price-setting firm facing a more general form of demand uncertainty have met with little success (see Baron [1971], Leland [1972]). Although somewhat restrictive, the additive form used here does allow a clear separation of the deterministic and stochastic features of the firm's problem. 
is further assumed that there is no capacity constraint to satisfying demand (that is, $\bar{x}$ is also expected output). The risk neutral firm's expected profit $(E(\pi))$ is thus given by:

$$
\begin{aligned}
E(\pi)= & E\left[[1+\lambda] c \cdot\left(([1+\lambda] c)^{-\varepsilon}+\mu\right)\right. \\
& \left.-c\left(([1+\lambda] c)^{-E}+\mu\right)-B\right] \\
= & \lambda c \cdot([1+\lambda] c)^{-E}+\lambda c E(\mu)-B
\end{aligned}
$$

Given this specification of the firm's demand uncertainty, and recalling (6), it is clear that the introduction of uncertainty has no effect on the behaviour of a risk neutral firm.

Consider now the behaviour of a risk averse firm which attempts to maximise the expected utility of profits (E(U(T)))

$$
E(U(\pi))=E\left[U\left(\lambda c \cdot\left(([1+\lambda] c)^{-E}+\mu\right)-B\right)\right]
$$

Differentiating (8) with respect to $\lambda$ and equating to zero gives the firm's first order condition: 7

$$
\begin{gathered}
E\left[U ^ { \prime } ( \lambda c \cdot ( ( [ 1 + \lambda ] c ) ^ { - \varepsilon } + \mu ) - B ) \cdot \left(c\left(([1+\lambda] c)^{-\varepsilon}+\mu\right)\right.\right. \\
\left.-\varepsilon \lambda c^{2}([1+\lambda] c)^{-\varepsilon-1}\right]=0
\end{gathered}
$$

Canceling by $c$ and rearranging gives:

$$
E\left(U^{\prime}(\pi) \cdot \mu\right)+E\left(U(\pi) \cdot([1+\lambda] c)^{-E}\left(1-\frac{E \lambda}{1+\lambda}\right)\right)=0
$$

Since:

$$
\begin{aligned}
E\left(U^{\prime}(\pi) \cdot \mu\right) & =E\left(U^{\prime}(\pi)\right) \cdot E(\mu)+\operatorname{Cov}\left(U^{\prime}(\pi), \mu\right) \\
& =\operatorname{Cov}\left(U^{\prime}(\pi), \mu\right) .
\end{aligned}
$$

7. It is shown in the appendix that the second order condition is satisfied for $U !^{\prime}(\pi)<0$ at the optimal level of mark-up. 
which is negative for $U^{\prime \prime}(\pi)<0$, it follows that:

$$
1>\frac{\varepsilon \lambda}{1+\lambda}
$$

for the risk averse firm. Therefore, comparing (11) with (4) shows that

$$
\lambda(\text { risk averse })<\lambda(\text { certainty })
$$

In the case of a risk averse firm, the introduction of uncertainty results in a lower mark-up (and consequently lower price and higher expected output) than in the case of no uncertainty. This result follows from the risk averse firm's attempt to lessen its profit risk by reducing the likelihood of very low levels of demand. It also implies that mark-ups will tend to be higher among firms which are less concerned with profit risk.

\section{SECTION II COMPARATIVE STATICS}

This section considers the effect on a risk averse firm's optimal mark-up of various parameter changes. In each of the first four cases considered, the simple certainty theory predicts no response for the firm's choice of mark-up. The last case examines the risk averse firm's response to an increase in the level of demand uncertainty.

\section{(i) Change in Fixed Cost (B)}

The effect on the firm's optimal $\lambda$ of a change in the level of $B$ will have the same sign as the derivative of (9) with respect to $\mathrm{B}:^{8}$

$$
-E\left[U^{\prime \prime}(\pi) \cdot\left(c\left(([1+\lambda] c)^{-E}+\mu\right)-E \lambda c^{2}([1+\lambda] c)^{-E-1}\right)\right]
$$

It is shown in the appendix that the sign of (12) is negative if the firm displays decreasing absolute risk aversion. In this case, therefore,

8. See Hey (1981), p.38. 
an increase in the level of fixed costs will induce a risk averse firm to reduce its optimal mark-up. Th1s response follows from the firm's attempt to reduce profit risk with a larger expected demand.

(ii) Change in Average Variable Cost (c)

The effect on the firm's optimal $\lambda$ of a change in the level of $c$ will have the same sign as the derivative of (9) with respect to c:

$$
\begin{aligned}
E & {\left[U^{\prime}(\pi) \cdot \varepsilon([1+\lambda] c)^{-\varepsilon-1}:(\varepsilon \lambda-[1+\lambda])\right] } \\
+E & {\left[U^{\prime \prime}(\pi) \cdot\left(([1+\lambda] c)^{-\varepsilon}+\mu-\varepsilon \lambda c([1+\lambda] c)^{-\varepsilon-1}\right) .\right.} \\
& \left.\left(\lambda\left(([1+\lambda] c)^{-E}+\mu\right)-\varepsilon \lambda([1+\lambda] c)^{-E}\right)\right]
\end{aligned}
$$

Using (11), it follows that the first term in (13) is negative. Furthermore, it is shown in the appendix that the second term is also negative if the firm displays decreasing absolute risk aversion. In this case, therefore, an increase in the level of average variable cost results in a decrease in the firm's optimal level of mark-up.

Since this level is unchanged both for the certainty case and for the risk neutral firm it follows that the extent to which variable cost increases are passed on to consumers is less in the case of a risk averse firm; although it seems unlikely that all the cost increase will be absorbed by the firm. This result also implies that the benefits of cost reductions will be partly absorbed by increased profit margins before being passed on to consumers. Consequently, the overall implication is that, in the case of a risk averse firm, price is to some extent insulated from fluctuations in costs by a variable profit margin. 
(iii) Introduction of a Profits Tax (t)

The introduction of a profits tax ( $t$ ) alters the firm's objective to maximising:

$$
E[U(\pi[1-t])]
$$

This gives the first order condition:

$$
E\left[U^{\prime}(\pi[1-t]) \cdot\left(([1+\lambda] c)^{-\varepsilon}+\mu-E \lambda c([1+\lambda] c)^{-\varepsilon-1}\right)\right]=0
$$

Differentiating with respect to $t$ gives:

$$
-E\left[U^{\prime}(\pi[1-t]) \cdot \pi \cdot\left(([1+\lambda] c)^{-\varepsilon}+\mu-\varepsilon \lambda c([1+\lambda] c)^{-\varepsilon-1}\right)\right]
$$

The effect on the firm's optimal $\lambda$ of the introduction of a profits tax will have the same sign as (15). It is shown in the appendix that the sign of (15) is positive if the firm displays increasing relative risk aversion. In this case, therefore, the introduction of a profits tax will induce the firm to increase the level of its mark-up.

Consequently, the view that in the context of mark-up pricing a profits tax is neutral with respect to the pricing decision would seem to be invalid. Although the mark-up in the case of no uncertainty or risk neutrality is unaffected by such a tax, a risk averse firm, by increasing its mark-up, will to some extent pass on the tax to consumers in the form of a higher price.

(iv) Change in the Level of Expected Demand ( $\bar{x})$

If it is assumed that an increase in expected demand is represented by a bodily rightward shift in the demand distribution by an amount $\alpha{ }^{9}$

$$
x=p^{-\varepsilon}+\mu+\alpha
$$

then the effect of such a change on the firm's mark-up can be determined

9. See Hey (1981), pp.38-40. 
by substituting (16) into (9), taking the derivative with respect to $\alpha$, and evaluating at $\alpha=0$ :

$$
\begin{aligned}
& E\left[U^{\prime}(\pi) \cdot \lambda c\left(([1+\lambda] c)^{-\varepsilon}+\mu-\varepsilon \lambda c([1+\lambda] c)^{-\varepsilon-1}\right)\right] . \\
& +E\left[U^{\prime}(\pi)\right]
\end{aligned}
$$

The effect on the firm's optimal $\lambda$ will have the same sign as (17). Using the result of the appendix that the sign of equation (12) is negative if the firm displays decreasing absolute risk aversion, it follows that this condition will result in the sign of (17) being positive. Alternatively, rearrange (17) to give:

$$
\begin{aligned}
& -\varepsilon \lambda^{2} c^{2}([1+\lambda] c)^{-\varepsilon-1} E\left[\mu^{\prime \prime}(\pi)\right] \\
& -E\left[U^{\prime}(\pi)\left(\frac{-U^{\prime \prime}(\pi)}{U^{\prime}(\pi)} \cdot \pi-1\right)\right]
\end{aligned}
$$

Since $U^{\prime \prime}(\pi)<0$, it follows that the sign of (18) will be positive if:

$$
\frac{-\mathrm{U}^{\prime} \cdot(\pi)}{\mathrm{U}^{\prime}(\pi)} \cdot \pi=\mathrm{R} \leq 1
$$

If the firm's index of relative risk aversion is everywhere less than or equal to one, then an increase in expected demand (as defined) will lead the firm to increase the size of its mark-up. The same result holds if the firm displays decreasing absolute risk aversion.

Consequently, unlike the case of no uncertainty (and demand rather than expected demand) or risk neutrality, a.risk averse firm will take the opportunity of increased expected demand to increase the size of its mark-up, thereby implying an upward sloping supply curve rather than one which is horizontal. Conversely, the firm will absorb some of the shock of a downturn in demand by reducing its profit margin. This 
implication clearly fits much better with the empirical evidence cited by Hay and Morris (1979).

(v) Change in the Jevel of Demand Uncertainty

The effect of an increase in the level of demand uncertainty on a risk averse firm's choice of mark-up can be determined using the approach of Rothschild and Stiglitz (1970). Using this approach, if the firm's first-order condition, (9), is concave (convex) in $\mu$, then the firm will respond to a mean-preserving spread in the demand distribution by decreasing (increasing) the size of its mark-up.

Taking the derivative of (9) with respect to $\mu$ gives:

$$
E\left[U^{\prime}(\pi)\right]+E\left[U^{\prime}(\pi) \cdot \lambda c \cdot\left(([1+\lambda] c)^{-\varepsilon}+\mu-E \lambda c([1+\lambda] c)^{-\varepsilon-1}\right)\right]
$$

which is equivalent to equation (18) and so is positive if $R \leq 1$. Taking the derivative of (18) with respect to $\mu$ gives:

$$
\begin{aligned}
& -E \lambda^{2} c^{2}([1+\lambda] c)^{-E-1} \cdot \lambda c \cdot E\left[U^{\prime \prime}(\pi)\right] \\
& -(R-1) \cdot \lambda c \cdot E\left[U^{\prime \prime}(\pi)\right] \\
& -E\left[U^{\prime}(\pi) \cdot \frac{\partial R}{\partial \mu}\right]
\end{aligned}
$$

Equation (19) will be negative, implying concavity of (9) in $\mu$, if:
a) $R \leq 1$
b) $\mathrm{R}$ is increasing
c) $\mathrm{A}$ is decreasing 10

10. If $\mathrm{A}$ is decreasing then:

$$
-\left(\frac{U^{\prime}(\pi) \cdot U^{\prime}(\pi)-\left(U^{\prime}(\pi)\right)^{2}}{\left(U^{\prime}(\pi)\right)^{2}}\right)<0 .
$$

Clearly this implies $\mathrm{U}^{\prime \prime}(\pi)>0$. Note also that this result is formally equivalent to that of Epstein (1978). 
Therefore, if these conditions on the characteristics of the firm's risk aversion are satisfied, the firm will respond to an increase in the level of demand uncertainty by reducing the size of its mark-up. In this case, the firm's response, similar to that following an increase in fixed or variable costs, represents an attempt to reduce its profit risk by encouraging demand with a lower price. Such a response, which is absent in the case of risk neutrality, suggests a further cause of fluctuating margins in conditions of demand uncertainty.

\section{SECTION .III CONCLUSION}

Based on the marginalist approach to the theory of mark-up pricing, this paper has considered the role of demand uncertainty in determining the optimal size of a firm's mark-up. It was shown in Section I that the results of the simple certainty theory of the mark-up continue to hold with the introduction of uncertainty if the firm is risk neutral. Specifically, this implies that the optimal size of the mark-up is inversely and solely determined by the elasticity of demand.

If, however, the firm is risk averse then the optimal size of markup can be shown to depend on other factors as well. Subject to certain restrictions on the characteristics of the firm's risk aversion, it was shown in Section II that the mark-up depends not only on the elasticity of demand, but also on the level of fixed and variable costs, the presence or not of a tax on profits, the level of expected demand and the level of uncertainty about demand. Rather than the size of the mark-up being largely independent of the firm's economic environment, the general implication of the results of this paper is that a firm's optimal mark-up may be responsive to a wide range of factors. That such variability of margin is more in keeping with observed behaviour 
suggests that some progress has been made towards a better understanding of the pricing decisions of firms. 


\section{APPENDIX}

(i) Second Order Condition

Differentiating (9) with respect to $\lambda$ gives:

$$
\begin{aligned}
& E\left[U^{\prime \prime}(\pi) \cdot\left(c\left(([1+\lambda] c)^{-\varepsilon}+\mu\right)-\varepsilon \lambda c([1+\lambda] c)^{-\varepsilon-1}\right)^{2}\right] \\
& -E\left[U^{\prime}(\pi) \cdot([1+\lambda] c)^{-\varepsilon} \cdot\left(\frac{\varepsilon}{[1+\lambda]^{2}}\right)\right] \\
& -E\left[U^{\prime}(\pi) \cdot\left(E c([1+\lambda] c)^{-\varepsilon-1} \cdot\left(1-\frac{\varepsilon \lambda}{1+\lambda}\right)\right)\right]
\end{aligned}
$$

Since $U^{\prime \prime}(\pi)<0$, and recalling (11), it follows that (A1) is negative at the optimal level of mark-up.

\section{(ii) Sign of Equation (12)}

Based on the original method of Sandmo (1971) (although for a more general proof see Hey (1981), pp.46-7), it can be shown that the sign of equation (12) is negative if the firm displays decreasing absolute risk aversion (A).

Denote by $\vec{\pi}$ the value of $\pi$ when:

$$
c\left(([1+\lambda] c)^{-\varepsilon}+\mu\right)-\varepsilon \lambda c^{2}([1+\lambda] c)^{-\varepsilon-1}=0
$$

and denote by $\bar{A}$ the value of the Index of absolute risk aversion when $\pi=\bar{\pi}:$

$$
\overline{\mathrm{A}}=\frac{-\mathrm{U}^{\prime}(\bar{\pi})}{\mathrm{U}^{\prime}(\bar{\pi})}
$$

If $A$ is decreasing in $\pi$ then: 


$$
\begin{aligned}
& -U^{\prime}(\pi) / U^{\prime}(\pi) \geq \overline{\mathrm{A}} \text { as } \\
& c\left(([1+\lambda] c)^{-\varepsilon}+\mu\right)-\varepsilon \lambda c^{2}([1+\lambda] c)^{-\varepsilon-1} \underset{>}{>} 0
\end{aligned}
$$

Therefore:

$$
\begin{aligned}
& U^{\prime}(\pi)\left(c\left(([1+\lambda] c)^{-E}+\mu\right)-E \lambda c^{2}([1+\lambda] c)^{-\varepsilon-1}\right)> \\
& -\bar{A} U^{\prime}(\pi)\left(c\left(([1+\lambda] c)^{-\varepsilon}+\mu\right)-\varepsilon \lambda c^{2}([1+\lambda] c)^{-\varepsilon-1}\right)
\end{aligned}
$$

Taking expectations, and using the first-order condition, (9), to show that the expected value of the right-hand side of (A2) is zero, gives the result.

\section{(iii) Sign of Equation (13)}

To determine its overall sign, it remains to determine the sign of the second term in (13). This term may be rearranged to give:

$$
\begin{aligned}
& E\left[U^{\prime \prime}(\pi) \cdot \lambda\left(([1+\lambda] c)^{-\varepsilon}+\mu-\varepsilon \lambda c([1+\lambda] c)^{-\varepsilon-1}\right)^{2}\right] \\
& -\varepsilon \lambda c([1+\lambda] c)^{-\varepsilon-1} E\left[U^{\prime}(\pi) \cdot\left(([1+\lambda] c)^{-\varepsilon}+\mu-\varepsilon \lambda c([1+\lambda] c)^{-\varepsilon-1}\right)\right]
\end{aligned}
$$

Since $U^{\prime}(\pi)<0$, the first term in (A3) will be negative. Furthermore, using the result of the sign of equation. (12), the second term in (A3) will be negative if the firm displays decreasing absolute risk aversion. Given this, the overall sign of (13) will be negative.

\section{(iv) Sign of Equation (15)}

Based on the original method of Sandmo (1971) (see also Hey (1981) Pp.128-29; but note the misprint), it can be shown that the sign of 
equation (15) is positive if the firm displays increasing relative risk aversion (R).

First define:

$$
\pi_{\mathrm{n}} \equiv \pi(1-\mathrm{t})
$$

Denote by $\bar{\pi}_{n}$ the value of $\pi_{n}$ when:

$$
([1+\lambda] c)^{-\varepsilon}+\mu-\varepsilon \lambda c([1+\lambda] c)^{-E-1}=0
$$

and denote by $\bar{R}_{\mathrm{n}}$ the value of the index of relative risk aversion when $\pi_{\mathrm{n}}=\bar{\pi}_{\mathrm{n}}$ :

$$
\vec{R}_{n}=\frac{-U^{\prime \prime}\left(\bar{\pi}_{n}\right) \cdot \vec{\pi}_{n}}{U^{\prime}\left(\bar{\pi}_{n}\right)}
$$

If $R_{n}$ is increasing in $\pi_{n}$ then:

$$
\begin{gathered}
\frac{-U^{\prime}\left(\pi_{n}\right) \cdot \pi_{n}}{U^{\prime}\left(\pi_{n}\right)} \stackrel{>}{=} \bar{R}_{n} \text { as } \\
([1+\lambda] c)^{-\varepsilon}+\mu-\varepsilon \lambda c([1+\lambda] c)^{-E-1} \stackrel{\vec{g}}{<} 0
\end{gathered}
$$

Therefore:

$$
\begin{aligned}
& -U^{\prime \prime}\left(\pi_{n}\right) \cdot \pi_{n}\left(([1+\lambda] c)^{-\varepsilon}+\mu-\varepsilon \lambda c([1+\lambda] c)^{-\varepsilon-1}\right)> \\
& \bar{R}_{n} U^{\prime}\left(\pi_{n}\right)\left(([1+\lambda] c)^{-\varepsilon}+\mu-\varepsilon \lambda c([1+\lambda] c)^{-\varepsilon-1}\right)
\end{aligned}
$$

Taking expectations, dividing through by (1-t), and using the first-order condition, (14), to show that the righthand-side of (A4) is zero, gives the result. 


\section{REFERENCES}

1. Baron, D.P. (1971), "Demand Uncertainty in Imperfect Competition", International Economic Review, Vo1.12, pp.196-208.

2. Epstein, L.G. (1978), "Production Flexibility and the Behaviour of Competitive Firm under Price Uncertainty", Review of Economic Studies, Vol.45, pp.251-261.

3. Hall, R.C. and C.J. Hitch (1939); "Price Theory and Business Behaviour", Oxford Economic Papers, No.2, pp.12-45.

4. Harcourt, G.C. and P.D. Kenyon (1976), "Pricing and the Investment Decision", Kyklos, Vol.29, pp.449-477.

5. Hay, D.A. and D.J. Morris (1979), Industrial Economics: Theory and Evidence (Oxford University Press).

6. Hey, J.D. (1981), Economics in Disequilibrium (Martin Robertson: Oxford).

7. Hey, J.D. (1982), "Whither Uncertainty?", Economic Journal Conference Papers, pp.129-139.

8. Kenyon, P.D. (1978), "Pricing" in A Guide to Post-Keynesian Economics, edited by A.S. Eichner (M.E. Sharpe Inc: White Plains, New York).

9. Leland, H.E. (1972), "The Theory of the Firm Facing Uncertain Demand", American Economic Review, Vol.62, pp.278-291.

10. Rothschild, M. and J.E. Stiglitz (1970), "Increasing Risk:1. A Definition", Journal of Economic Theory, Vo1.2, pp.225-243.

11. Sandmo, A. (1971), "On the Theory of the Competitive Firm Under Price Uncertainty", American Economic Review, Vol.61, pp.65-73. 